\title{
電磁流体力学系の準終状態と準静状態
}

\author{
吉田善章 \\ ( 東京大学工学部) \\ （1986 年 4 年 10 日受理）

\section{Quasi-Ultimate and Quasistatic States in MHD Systems}

Zensho Yoshida

(Received April 10, 1986)

\begin{abstract}
The dissipative structure of an MHD system is studied theoretically and phenomenologically. General remarks are made on the relation between self-organization in dynamical systems and characteristics of equilibria. We introduce a concept of quasi-ultimate states, and find MHD quasi-ultimate states, which correspond to RFP, tokamak, and trivial states. An extended set of stable equilibria, that is the quasistatic class of equilibria, includes ULQ states which are lying between the tokamak and RFP states. Relaxation into these stable equilibria is characterized by two different processes, viz., classical diffusion and MHD relaxation.
\end{abstract}

\section{1. 序 論}

時間発展するシステムを一般に力学系( dynamical system) と呼んで, 広く理工学諸分野において抽象 論から現象論に至るまで様々な研究が活発に行われている。力学系とは即ち相空間 (状態空間) 内に或る種 の流れが定義されたものと理解できる*)。流れとは 1 つの実数パラメータ $\mathrm{t}$ (時刻)**)によって変遷する 写像の集合であり,それが系の状態を移してゆく。例えば 1 つの質点の運動を考える場合, 相空間は位置と

*) 確率的な力学系の場合は相空間上の測度を移す流れが定義されている。てれが $\delta$ 測度を $\delta$ 測度に移す 場合決定論的である。

**） $\mathrm{t}$ は連続值をとるのが普通であるが離散值をとる場合（Poincaré map. 等）を考える事もある。

Department of Nuclear Engineering, Faculty of Engineering, University of Tokyo, Tokyo 113. 
運動量の座標から成る 6 次元のEuclid 空間であり, 粒子の軌道は 1 つの流線を与える。連続体の力学等で は相空間は関数空間となり, 流れは即ち作用素の集合 ( 半群) である。流れの接線方向を与えるのがその力 学系の運動方程式である。運動方程式は相空間内の $\mathrm{t}$ 亿関する常微分方程式である。相空間が関数空間の場 合はそれは関数方程式となる。一般に相空間内の常微分方程式を発展方程式と呼ぶ。発展方程式を解くと流 れがもとまる。とのように発展方程式 (常微分方程式) の研究と力学系の研究とは密接な関係を持つ1)。

一般に力学系の理論にわいては次の双極をなす二種類の現象の研究が重要である。その一つは系に現れ る単純さ, 安定性, 秩序の自己形成 ( self-organization $)^{1,2,3)}$ の研究であり, むう一つは系に現れる複 雑さ, 不安定性, 無秩序化 ( chaos $)^{1)}$ の研究である。本稿はその前者, 則ち散逸性力学系における安定な平 衡状態の自己形成について論考する。

我々がててで主張するのは平衡を記述する方程式（発展方程式において $\partial_{\mathrm{t}}=0$ ）が双極型の成分（第 2 節参照) を持ってとが自己形成 ( 又, ある時はカオス) に関して本質的な意味を持つというてとである。即 ち, 双極型の成分に対応する平衡の特性関数が力学系の時間漸近挙動の中でいかに決定されてゆくかという 問題が, 力学系の所謂散逸構造の研究と数学的対応を持つととを示す。

本稿が具体的現象として扱うのはトロイダル電流システムにおけるプラズマのMHDである。プラズマの MHD平衡は宇宙プラズマの研究や磁場閉じ込め核融合の基礎実験において精力的に調べられており，いく つかの異なる種類の平衡配位が実際に形成されるととが知られている。つまりフララ゙、は, 一定の条件下で, ある種のMHD平衡を自己形成する性質を持っているのである。との現象は制御核融合の基本的原理として 工学的に重要であるし, 又純粋に物理学的にも興味深い。乙れに理論的考察を加える為には適当な非線型散 逸性力学系を設定し，その時間漸近挙動に関する理論を構成するのが適当であろう。本稿では MHD系の或 る種の時間漸近形 ( 第 3 節) を調へ平衡の特性関数を定める (第 4 節)。乙れによって MHD系のいくつか の分岐したアトラクターの素描を得るととができる。第 5 節では更に様々な時間スケールに目を向け, MHD系の安定且つ accessible な平衡の微細構造を現象論的に論じる。

\section{2. 双極型の成分を持っ平衡の問題}

MHD 平衡理論の難しさ ( 面白さ) は平衡方程式系

$$
(\operatorname{rot} \boldsymbol{B}) \times \boldsymbol{B}=\mu_{0} \operatorname{grad} \mathrm{p}, \quad \operatorname{div} \boldsymbol{B}=0
$$

の数理の難しさに対応している。（1）の特性方程式は $(\boldsymbol{B}, \operatorname{grad} \psi)^{2}(\operatorname{grad} \psi)^{2}=0$ 従って(1) は （Bの方向に縮退した）2双極\& 2 棈円型の方程式系である。との事情は定常の非圧縮理想流体の方程式系 - ( $\boldsymbol{u}, \operatorname{grad}) \boldsymbol{u}=\operatorname{grad} \mathrm{p}+\boldsymbol{f}, \operatorname{div} \boldsymbol{u}=0$ と同様である。乙の種の双極型の部分を持つ平衡の問題は, 他にも液晶の結晶欠陥の問題等でも現われ, 数理物理学の最近の話題の一つでもある。単に楕円型の平衡問 題では平衡状態が境界条件によって（一意的か否かは別として）定まるのに比へ，双極型の部分を持つ問題 
は境界条件だけではwell - posed にはならない。要点は双極型の部分に対応する特性関数をどのように定め るかというととにある。物理的にいえば特性関数は初期データの散逸と保存との競合によって定まる。つま り動的問題との関係に於いてはじめて平衡の問題が閉じた物理的問題として意味を持つ。

良く知られた例として, Grad 他 ${ }^{4,5)}$ は quasistaticsの立場から古典拡散理論を構成している。それはプ ラズマが常に一定の対称性を持つMHD平衡状態にあると仮定し, 散逸や境界条件の緩やかな変化等によっ て静かに発展する様子を記述するものである。系汇対称性があると平衡は Grad-Shafranovの方程式 ${ }^{6)}$, 例 えば $\partial_{z}=0$ であれば

$$
-\Delta \Psi=\mathrm{P}^{\prime}(\Psi)+\mathrm{I}^{2 \prime}(\Psi) \quad(\Psi: \text { 磁束関数 })
$$

によって記述され $\mathrm{P}(\Psi), \mathrm{I}(\Psi)$ が二つの特性関数である。右辺は $\mathrm{z}$ 方向の電流密度に比例する量である。 P, I を拡散型の方程式系で支配するのが古典拡散理論であって, その拡散が系の散逸構造を定めている。 その適用範囲は勿論 quasistaticsに限られ, 磁気面を持つ平衡の存在, 及び系が平衡に留まるととを a priori に仮定しているが, トカマク等の準静的な電流分布の評価などに有用である。

しかし, 非平衡から平衡への近接の可能性そのものを扱う為には更に動的な理論を構成する必要がある。 本稿では固有の散逸構造という概念を導入して特性関数を与え, その平衡を,「非平衡状態から出発して系 の非線型性が強い時間スケールを見た場合のアトラクター」として特徵付ける。

\section{3. 系に固有の散逸構造}

力学系に外力が働いているとその力学系の挙動は外力の形に依存する。力学系の挙動を調べる第一歩とし て、そのような外力のない場合を考えるのが自然な理論の進めかたである。散逸性力学系に関して外力のな い場合の挙動を構造的に調べるととを「系に固有の散逸構造( intrinsic dissipative structure $)^{7)}$ を調へ る」というととにする。以下簡単な例によって固有散逸構造の理論を導入しよう。

散逸性力学系の簡単な例として有界な領域内で線型拡散方程式を考える：

$$
\partial_{t} u=\Delta u, \quad u(0)=u_{0}
$$

但し， $\mathrm{u}_{0}$ は初期値， $\mathrm{u}$ の境界值は 0 とする。（2）は次のように解くことができる：

$$
u(t)=\sum \exp \left(-t \lambda_{i}\right)\left(\phi_{i}, u_{0}\right) \phi_{i} \quad(t \geqq 0)
$$

但し， $\lambda_{i}$ と $\phi_{i}$ はそれぞれLaplacian $-\Delta$ の第 $\mathrm{i}$ 固有值と固有関数である。 $\left(0<\lambda_{1} \leqq \lambda_{2} \leqq \lambda_{3}\right)$ より直接的にわかる固有散逸構造の triviality として $u(t) \rightarrow 0(t \rightarrow \infty)$ 。( 3 ) を次のように書き直そう：

$$
u(t)=\exp \left(-t \lambda_{1}\right) \sum \exp \left(-t\left(\lambda_{i}-\lambda_{1}\right)\right)\left(\phi_{i}, u_{0}\right) \phi_{i} \quad(t \geqq 0)
$$

ことでは簡単の為に $\lambda_{1}$ は非退化とする。(4)より, $\mathrm{t}$ が大きくなると

$$
u(t) \rightarrow \exp \left(-t \lambda_{1}\right)\left(\phi_{1}, u_{0}\right) \phi_{1}
$$


となるてとがわかる。とれが固有散逸構造の第一の nontriviality である。即ち $\mathrm{u}(\mathrm{t})$ は状態 $\mathrm{v}_{\infty}=\left(\phi_{1}\right.$, $\left.\mathrm{u}_{0}\right) \phi_{1}$ に近付きながら0へ減衰する。 $\mathrm{v}_{\infty}$ を準終状態 ( quasi-ultimate state) と呼ぼう。終状態 $\mathrm{u}(\infty)=0$ が初期データ $\mathrm{u}_{0}$ を全て忘れたものであるのに対し, 準終状態はての場合一つの情報 $\left(\phi_{1}, \mathrm{u}_{0}\right)$ を保存しているてとに注意しよう。準終状態は次のような性格も持つ。元の方程式 (2) を摂動した方程式

$$
\partial_{t} v=(\Delta+\lambda) v, \quad v(0)=u_{0}
$$

を考える。パラメータ $\lambda=\lambda_{1}$ とすると, 㩒動された系 $\left(2^{\prime}\right)$ の終状態が $(2)$ の準終状態 $\mathrm{v}_{\infty}$ である。即ち， パラメータ入が大きくなって $\lambda_{1}$ に達した時 ( $2^{\prime}$ ) の定常解（不動点） $\mathrm{v}_{\infty}\left(-\boldsymbol{\Delta} \mathrm{v}_{\infty}=\lambda \mathrm{v}_{\infty}\right)$ に $\mathrm{v}_{\infty}=0$ からの分岐が生じ，（2'）はその nontrivial な分岐集合の中に終状態を持つようになる。それが（2）の準 終状態に対応するのである。実際， $u(t)=\exp (-t \lambda) v(t)$ とおいて $(2)$ 亿代入すると $\left(2^{\prime}\right)$ を得る。

以上の概念を拡張し, 次の様な固有散逸構造の理論を作る。抽象的に発展方程式

$$
\partial_{t} u=L u+N u, \quad u(0)=u_{0}
$$

を考える。但し， $L u$ は線型散逸項， $N u$ は（ $N u$ だけではエネルギーを保存する）非線型項とする。その 具体形は次節で与える。乙の解 $\mathrm{u}(\mathrm{t})$ （それがあったとして）を $\mathrm{u}(\mathrm{t})=\exp (-\mathrm{t} \boldsymbol{A}) \mathrm{v}(\mathrm{t})$ と書き直す。 ここで $\Lambda$ は適当に選ばれる正作用素である。もしv $(\mathrm{t})$ に対して. $\exp (-\mathrm{t} \boldsymbol{\Lambda}) \sim 1$ とできる時間スヶー ル $\tau_{\mathrm{D}}$ 以内で $\mathrm{v}(\mathrm{t}) \rightarrow \mathrm{v}_{\infty}$ なる時間漣近挙動が見られれば $\mathrm{v}_{\infty}$ を準終状態と呼ぶ。 $\mathrm{v}_{\infty}$ は摂動された問題

$$
\partial_{t} v=(L+\Lambda) v+N v, \quad v(0)=u_{0}
$$

の時間漸近形として与えられる。非線型システム $(5)$ の場合, (5) $て \mathrm{u}(\mathrm{t})=\exp (-\mathrm{t} \boldsymbol{\Lambda}) \mathrm{v}(\mathrm{t})$ を代入し ても一般には $\left(5^{\prime}\right)$ にはならないし, 又 $(\mathrm{t} \rightarrow \infty)$ で $\mathrm{u}(\mathrm{t}) \rightarrow \exp (-\mathrm{t} \Lambda) \mathrm{v}_{\infty}$ でもない。( 5$)$ と $\left(5^{\prime}\right)$ が等価 なのは時間スヶール $\tau_{\mathrm{D}}$ 内のみであるととに注意しょう。即ち非線型システムに対しては時間スヶール $\tau_{\mathrm{D}}$ が極めて重要なパラメータであり, 準終状態は固有散逸構造の理論において更に大きな nontrivialityを持つ のである。次節では具体的にMHD システムを考え，その時間漸近挙動について論考しょう。

\section{MHD 準終状態}

抽象的に（5）の如く表現した発展方程式の物理的具体例としてNavier-Stokes 系 ${ }^{8}$ ， Ohm-Navier Stokes 系 ( 0 - NS $)^{9}$ )等がある。乙れらの系は対流型非線型散逸性力学系として独特な性質を持つ10)。本 節では非圧縮散逸性電磁流体力学のO-NS を考える：

$$
\begin{aligned}
& \partial_{t} \boldsymbol{B}=-\operatorname{rot} \eta \operatorname{rot} \boldsymbol{B}+\operatorname{rot}(\boldsymbol{v} \times \boldsymbol{B}), \\
& \partial_{t} \boldsymbol{v}=\nu \boldsymbol{\Delta} \boldsymbol{v}-(\boldsymbol{v}, \operatorname{grad}) \boldsymbol{v}+[(\operatorname{rot} \boldsymbol{B}) \times \boldsymbol{B}-\operatorname{grad} p] / \rho, \\
& \operatorname{div} \boldsymbol{B}=0, \quad \operatorname{div} \boldsymbol{v}=0,
\end{aligned}
$$

とてで, $\boldsymbol{B}$ : 磁束密度, $\boldsymbol{v}$ : 流速, $p$ : 圧力, $\eta$ : 抵抗, $\nu$ : 動粘性係数, $\rho$ : 質量密度, 境界条件は 


$$
\boldsymbol{v}=0, \quad \boldsymbol{B} \cdot \boldsymbol{n}=\text { given, } \quad \operatorname{rot} \boldsymbol{B} \times \boldsymbol{n}=0,
$$

但し, $\boldsymbol{n}$ は境界への法線ベクトルである。一 $\operatorname{rot} \eta \operatorname{rot} \boldsymbol{B}$ と $\boldsymbol{\Delta} \boldsymbol{v}$ が線型の散逸項であり, その他の右辺の 項が対流型の非線型項である。磁束密度を分解して $\boldsymbol{B}=\boldsymbol{B}_{\mathrm{p}}+\boldsymbol{B}_{\mathrm{ex}}$, 但し $\boldsymbol{B}$ ex は外的に与えられた磁束 密度 (プラズマ内で $\operatorname{rot} \boldsymbol{B}_{\mathrm{ex}}=0$, 境界上 $\left.\boldsymbol{B}_{\mathrm{ex}} \cdot \boldsymbol{n}=\boldsymbol{B} \cdot \boldsymbol{n}\right), \boldsymbol{B}_{\mathrm{p}}=\operatorname{rot} \boldsymbol{A}($ 境界上 $\boldsymbol{A} \times \boldsymbol{n}=0$ ) と書く。乙 のような分解は一意的に可能でHodge-Kodaira 分解と呼ばれる ${ }^{9}$ 。 $\mathrm{O}-\mathrm{NS}$ の従属変数は $\boldsymbol{B}_{\mathrm{p}}, \boldsymbol{v}$ である。 $p$ は $\boldsymbol{B}_{\mathrm{p}}, \boldsymbol{v}$ に対して implicit に定まる。

前節で定義した準終状態がO -NSに関して存在し，トロイダル（周期的円筒）システムに対してそれは表 1 の様に書けるととがわかる ${ }^{11), 12) 。 ~}$

表 1.トロイダル電流系の準終状態

\begin{tabular}{l|r|c|c|c|c|l}
\hline & $\mathbf{B}=\mathbf{B}_{\mathrm{p}}+\mathbf{B}_{\mathrm{ex}}$ & $\mathbf{v}$ & $\Lambda_{\mathrm{b}}$ & $\mathrm{B}_{\mathrm{p}} / \mathbf{B}_{\mathrm{ex}}$ & $\mu(r)$ & \multicolumn{1}{|c}{ example } \\
\hline class-1 & $\mathbf{B}_{\mathrm{ex}}$ & 0 & 0 & 0 & 0 & trivial state \\
class-2 & $\varepsilon \psi_{1}+\mathbf{B}_{\mathrm{ex}}$ & 0 & $\lambda_{1}$ & $<<1$ & $\sim J_{0}$ & tokamak \\
class-3 & $\psi_{\mathrm{o}}+\alpha \psi_{1}+\mathbf{B}_{\mathrm{ex}}$ & 0 & $\boldsymbol{x}_{1}$ rot & $\sim 1$ & const. & RFP \\
\hline
\end{tabular}

但し,

$$
\begin{aligned}
& \psi_{1}: \operatorname{rot} \eta \operatorname{rot} \psi_{1}-\lambda_{1} \psi_{1}=0 \text { なる第一固有関数 } \\
& \Psi_{1}: \eta \operatorname{rot} \Psi_{1}-\kappa_{1} \Psi_{1}=0 \text { なる第一固有関数 } \\
& \Psi_{0}: \eta \operatorname{rot} \Psi_{0}-\kappa_{1}\left(\Psi_{0}+B_{\mathrm{ex}}\right)=0 \text { の解 }
\end{aligned}
$$

$\varepsilon$ は微小な実数, $\alpha$ は任意の実数であり， $\Lambda_{\mathrm{b}}$ は $\Lambda$ の内 $\boldsymbol{B}$ に作用する部分である。各々は分離した準終状態 のクラスを成し，系がどの状態に漸近するかは勿論境界条件とともに初期条件によって決まる。てれが散逸 構造理論の基本的な論理である。

円筒座標で $\boldsymbol{B}_{\mathrm{ex}}=\left(0,0, \mathrm{~B}_{\mathrm{z}}\right), \eta=\mathrm{constant}$, 領域は半径 a の円筒として, class-2, class-3 の平衡 を具体的に計算すると次の様になる（文献 12 参照）。

class-2:

$$
\varepsilon \psi_{1}+\boldsymbol{B}_{\mathrm{ex}}=\varepsilon\left(0, J_{1}\left(\mu_{1} r\right), 0\right)+\left(0,0, B_{z}\right)
$$

但し, $\mu_{1}=2.4 / \mathrm{a}$ で, てれはトカマク型の配位を与える。

class-3 :

$$
\Psi_{0}+\boldsymbol{B}_{\mathrm{ex}}=B_{z} \mu_{1} a / 2 J_{1}\left(\mu_{1} a\right) \cdot\left(0, J_{1}\left(\mu_{1} r\right), J_{0}\left(\mu_{1} r\right)\right)
$$

但し， $\mu_{1}=3.1 / a, \Psi_{1}$ はヘリカル対称な磁束密度である。この状態はRFPの実験や緩和のモデルで良 く知られた Bessel 関数配位と一致する ${ }^{13)}$ 。 
系の形状を換えて球状の領域を考えると, class-3 が変形したものとしてスフェロマック的な平衡が得ら れる。又, 全方向に周期的な領域を考えて, $\boldsymbol{B}_{\mathrm{ex}}=0$ とすると, 宇宙プラズマで知られているChandrasekhar の等分配状態 $\left(\boldsymbol{v}=\left(\rho / \mu_{0}\right)^{1 / 2} \boldsymbol{B}\right)$ が得られる。

こてで与えたMHD準終状態はMHD 平衡の中の特別なクラスをなす。第 2 節で議論した平衡の特性関 数が, 系の散逸構造との関係において決定された訳である。但し, 本稿の範囲では, 全プラズマ電流に対す る寄与の小さい第 2 の特性関数である圧力分布に対しては正確な評価を行っていない。とのととに関して本 稿では筆者があまり真剣でないのは, プラズマの場合, 圧力分布の決定にはエネルギー輸送に関して精密な 取扱いが必要であり, それは屢々MHD というシンプルな描像の枠を越えると考えるからである。てれはプ ラズマが熱エネルギーを閉じ込めるか否かという興味深い問題であるととは勿論であるが，とてでは MHD モデルの範囲で十分記述できる第 1 の特性関数, 即ち無力磁場配位分布の自己形成という系の美しい散逸構 造を解析できたととに満足するとととしょう。実際, トロイダル電流プラズマ中の磁場配位は多くの場合, 無力磁場近似で充分特徵付けるととができる。MHD平衡は近似的に

$$
(\operatorname{rot} \boldsymbol{B}) \times \boldsymbol{B}=0, \quad \operatorname{div} \boldsymbol{B}=0
$$

即ち,

$$
\operatorname{rot} \boldsymbol{B}=\mu(x) \boldsymbol{B}, \quad(\boldsymbol{B}, \operatorname{grad}) \mu=0
$$

によって記述される。平衡を近似的に特徴付ける関数 $\mu(x)$ は, 上述の準終状態に対して表 1 の様に分類 される。

\section{5. 準静状態の微細構造}

前節で見たようにMHD準終状態の概念は多種の 安定 MHD 平衡の形成を統一的に説明するものである。 しかし, 準終状態の定義は相当に制約的なものであ って, 実験的には更に広い意味で安定な MHD 平衡 を実現するととができる。MHDの特性時間(Alfvén 時間）より充分長い時間安定でいる状態を準静状態 （quasistatic state）と呼ぶ。準終状態は準静状態 のなかで特に時間漸近性のある状態ということがで きる。即ち

\section{$\{$ 準終状態 $\} \subset\{$ 準静状態 $\}$ 。}

準終状態のclass $-2\left(\mathrm{~B}_{\mathrm{p}} / \mathrm{B}_{\mathrm{ex}} \ll 1:\right.$ tokamak $)$ とclass $3\left(\mathrm{~B}_{\mathrm{p}} / \mathrm{B}_{\mathrm{ex}} \sim 1\right.$ : RFP )の間には複雑な準静状態の微 細構造が見られる。図一 1 は三つの準静状態 $(n=$

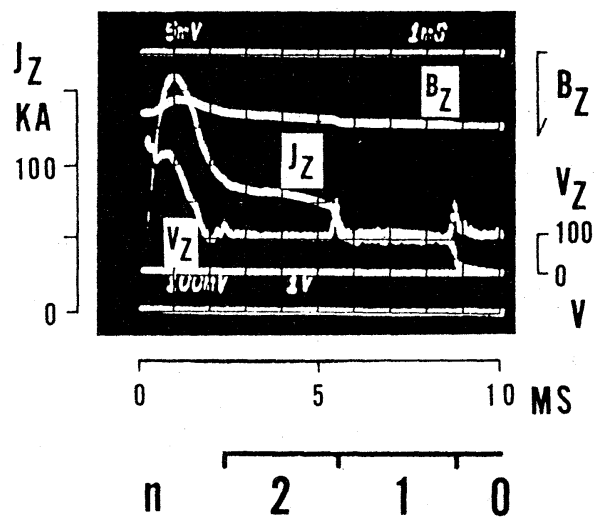

図 1.ULQ 放電。 ${ }^{14)}$ プラズマ電流によって 作られる $\mathrm{B}_{\mathrm{p}}$ が class-2 と class-3 の中間的領域 (超低 q 領域) にある時 のトロイダル放電特性。 $\mathrm{B}_{\mathrm{z}}$ : トロイ ダル磁束密度, $J_{z}$ : トロイダル電流, $\mathrm{V}_{\mathrm{z}}$ : トロイダル方向周回電圧。 
$2,1 ， 0)$ がそれぞれ catastrophicな遷移を経て形成される様子を示している。最後の $\mathrm{n}=0$ の状態が class-2 の準終状態（トカマク）に対応する。MHD不安定な励起状態から準終状態へ近接する間に形成さ れた準静状態 ( $\mathrm{n} \geqq 1)$ をULQ (ultra low-q) 配位と呼ぶ ${ }^{14}$ )。

トロイダルプラズマ実験装置REPUTEー1 亿於ける実験によって, ULQはトカマク（ class-2 ）とRFP

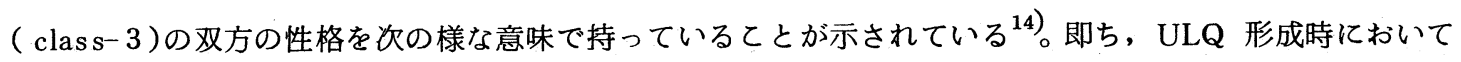
は平衡は $\mu=$ constant という class-3 型の分布（表 1 参照）を持つが，てれが古典拡散の時間スヶールで 更に quasistatic な変形を受けて $\mu \propto \mathrm{J}_{0}$ 的なピークした分布を持つようになりclass-2 型の性格を帯びて くる。しかし, ULQ 領域の $B_{\mathrm{p}} / B_{\mathrm{ex}}$ ではピークした電流分布の平衡はglobal MHDモードに対して不安定 である為, 結局 quasistatic な変形は平衡を不安定化するととになり, プラズマは再び動的な phaseに入る。 そして更に小さいnのULQを形成し，てれが又 qasistatic に不安定化するという過程を経ながら，ついに は class-2 の準終状態に至る。この様に class -2 と class -3 の準終状態の間に位置するMHD平衡群の中 には双方の性格を折本的に受け継いでいる準静状態の微細構造があるととがわかる。

\section{MHD 緩和と古典拡散}

第 4 節で示した class-2, class-3 の準終状態はそれぞれ- rot $\eta \operatorname{rot}($ 線型拡散項そのもの) と 一 $\eta \operatorname{rot} の$ 第一固有関数によって特徴付けられる。従って前者は古典拡散によって支配される状態であるて とがわかる。その正確な記述を志すと quasistatics に至る ${ }^{4)}$ 。一方, 後者即ち class-3 亿対応する散逸構造 は古典拡散では説明できないものであり, 対流型非線型性が強く関与している。class-3 への漸近は MHD 緩和という言葉で認識されているトロイダル電流系の非線型現象に対応するものである。又, 前節で述べた 如くULQではMHD緩和と古典拡散緩和の双方が現れ， それぞれの特徵的時間スケールによって分離して観測さ れる。以上をまとめるとトロイダル電流系の散逸構造と して表 2 の様な描象を得る。

MHD緩和はプラズマの流体的速度 $\boldsymbol{v}$ に関係する誘導

表 2．分岐した準静状態を支配する緩和過程

\begin{tabular}{l|c}
\hline$R F P$ & MHD 緩和 \\
\hline$U L Q$ & MHD 緩和 + 古典拡散 \\
\hline tokamak & 古典拡散 \\
\hline
\end{tabular}

電場 $\boldsymbol{v} \times \boldsymbol{B}$ が本質的な役割を果す現象である。流体的速度はO-N S 系 (6) から自己無撞着に与兄られる。 流体の運動エネルギーの増加はプラズマの MHD不安定性による。即ち, MHD 緩和はプラズマの MHD activity を伴った現象である。RFP平衡形成時に観られる MHD經和現象において，そのMHD activity

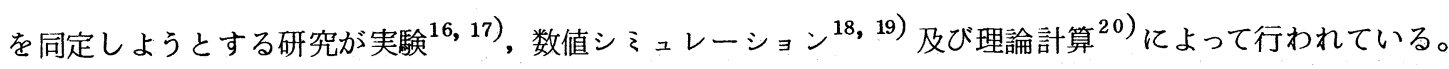

*) 一方, quasistaticsにおける古典拡散では, 運動方程式において $\partial_{\mathrm{t}}=0, \boldsymbol{v}=0$ として平衡を仮定 する。しかし，Ohm の法則における誘導電場は必ずしも0ではなくて，系が平衡に保たれる様に implicit な小さな $\boldsymbol{v}$ が存在し得ると考える。例えば, 文献 15 参照。 
それらの一致した見解として, $\mathrm{m}$ ( poloidal モード数) =1 の大域的 kink不安定性が駆動する流体的速度 $\boldsymbol{v}$ がRFP平衡への MHD緩和をもたらすと考えられる。更に，てのm=1の kink activity を伴う MHD 緩 和はRFPのみに留まらず, ULQ及び磁気軸での安全係数 $\mathrm{q}$ が1 以下となったトカマクにおいても観測さ れる。ULQの場合は初期の形成過程においてであり ${ }^{14)}$, トカマクの場合は所謂 saw-tooth oscillation よるプラズマ電流の再分布が起てる時である。ての場合, トカマクであっても古典拡散によってその散逸構 造を説明するてとはできない。との様に MHD緩和は $\mathrm{m}=1 \mathrm{kink}$ が励起される $\mathrm{q}<1$ の領域を伴う系に特 徵的なものである。

トロイダル電流系について一般的なととは $\mathrm{m}=1$ の kinkが軸上の安全係数 $\mathrm{q}(0)$ の上昇をもたらす様な 緩和現象を引き起とすということである。勿論, 磁気面量としての q $(\Psi)$ は ideal MHD の保存量であるか ら, 緩和現象の前後で系が同じ対称性を持つとして, そてで, q (0)の上昇を得る為には或る種の散逸過程 (磁力線再結合) を経るととになる。しかしそれ以前に次の点は注目に值する。即ち、ての様な MHD 緩和 の駆動過程である $\mathrm{m}=1 \mathrm{kink}$ 変形は, ideal の範囲 (時間スケール) で既に幾何学的な軸に対する磁力線 の巻き付き数の変化をもたらしている。特に, 軸の近傍では幾何学的な意味での安全係数, 即ち幾何軸に対 する磁力線の巻き付きの逆数の増加を与える。 $\mathrm{m}=1 \mathrm{kink}$ 変形は磁気軸のシフトを伴い, 磁気軸は幾何軸 に巻き付いた形となる。二つの磁束の微分比として定義した所謂磁気面量としての q は, てのヘリカル変形 した磁気軸への巻き付きの逆数であり,てれは勿論 ideal の極限では保存される。磁力線の再結合を伴う緩 和過程を経て, 再度幾何軸と磁気軸が一致した状態へ緩和する時, kink変形が与えた幾何軸への磁力線の巻 き付き数の減少が結局 $\mathrm{q}(0)$ の上昇を与えるととになる。ての様に MHD緩和というものを $\mathrm{m}=1$ の大域的 kink 変形を半う散逸過程であると同定すれば, それは, 古典拡散と合わせて, 全てのトロイダル電流系, RFP ULQ, トカマクにおける電流分布 (平衡の特性関数) の形成を一般的に説明する概念となる*)。

\section{7. まとめ}

本稿の前半では, 力学系に現れる自己形成, 平衡の特性関数と散逸構造の関係, 及び系の準終状態という 概念について一般的な議論を行い, 後半で MHD系の散逸構造について具体的に論考した。MHD 平衡は二 つの特性関数によって特徴付けられる。特性関数を定めるととに散逸構造理論の本質が在るととに注目しつ つ,トロイダル電流系の準終状態としてRFP, トカマク, 及び trivial stateがあるととを示した。更に準 静状態まで概念を拡張すると, RFP とトカマクの間にULQ という微細構造が観られた。てれらの互いに 分離した散逸構造の分岐に対応する緩和過程は, MHD 緩和と古典拡散の二つによって説明できる。

末筆ながら, 御鞭撻頂いた内田岱二郎先生, 谷内俊弥先生, そして井上信幸先生に感謝致します。

*) 細かく言えば $\mathrm{m}>1$ の MHD activity も電流分布形成に関与する。よく知られている様に, tearing modes はその共鳴面における電流密度の傾きを減少させ自ら安定化する。 


\section{参考文献}

1) M. W. Hirsch : Bull. Amer. Math. Soc. 11 (1984), 1.

2) G. Nicolis and I. Prigogine : Self-Organization in Non-Equilibrium System from Dissipative Structure to Order through Fluctuations (Wiley Interscience, New York, 1977).

3) A. Hasegawa : Adv. in Phys. 34 (1985), 1.

4) H. Grad and J. Hogan: Phys. Rev. Lett. 24 (1970), 1337.

5) H. Grad, P. N. Hu and D. C. Stevence : Proc. Nat. Acad. Sci. USA 72 (1975), 3789.

6) H. Grad and H. Rubin : in Second United Nation Conference on the Peaceful Use of Atomic Energy, Genova, Vol. 31 (1958), 190.

7) Z. Yoshida and N. Inoue : J. Phys. Soc. Jpn. 55 (1986), 1925.

8) Z. Yoshida and Y. Giga : Comm. Partial Differential Eqs. 9 (1984), 215.

9) Z. Yoshida and Y. Giga : J. Math. Phys. 24 (1983), 2860.

10）吉田善章, 井上信幸, 内田岱二郎：核融合研究 51 (1984), 127.

11) Z. Yoshida, T. Uchida and N. Inoue : Phys. Fluids 27 (1984), 1785.

12) Z. Yoshida, T. Uchida and N. Inoue : Prog. Theoret. Phys. 72 (1984), 1.

13) H. A. B Bodin and A. A. Newton: Nucl. Fusion 20 (1980), 1255.

14) Z. Yoshida, et . al.: J. Phys. Soc. Jpn. 55 (1986), 450.

15) Z. Yoshida, N. Inoue and T. Uchida : J. Math. Phys. 25 (1984), 1771.

16) Z. Yoshida, et. al. : in Plasma Physics and Controlled Nuclear Fusion Research 1984, (IAEA, Vienna, 1985), Vol. III , 467.

17) K. Miyamoto, et. al. : Relaxation Process of RFP Plasma in REPUTE-1, (to appear as an invited paper at 13th IEEE Inter. Nat. Conf. on Plasma Science, Saskatoon, Canada, 1986).

18) T. Sato and K. Kusano: Phys. Rev. Lett. 25 (1985), 808.

19) K. Kusano: private communication.

20) K. Miyamoto: Nucl. Fusion 25 (1985), 1677. 